\title{
Singlet Oxygen Production Photosensitized by Fluorescein in Reversed Micellar Solutions
}

\author{
Norio Miyoshi and Giiti Tomita* \\ Institute of Biophysics, Faculty of Agriculture, Kyushu University, Fukuoka 812, Japan
}

Z. Naturforsch. 35 b, 731-735 (1980); received December 7, 1979

Singlet Oxygen, Fluorescein, Diphenylisobenzofuran, Water Content, Reversed Micelles

The quantum yield of singlet oxygen production was investigated in dodecylammonium propionate reversed micellar solutions containing 1,3-diphenylisobenzofuran and fluorescein as photosensitizer. The quantum yield was highly enhanced by the binding of fluorescein to reversed micelles, and increased with decreasing the solubilized water content in reversed micelles. Results obtained was discussed with the optical properties of fluorescein (absorption, fluorescence and phosphorescence) in reversed micellar solutions.

\section{Introduction}

Recently, chemical reactions in micellar systems attract increasingly various worker's attention from the interest of bio-mimic chemistry. The DF oxidation by singlet oxygen produced by the photosensitization of pyrene has been studied by us in various micellar solutions [1-3]. The DAP reversed micellar solutions provide a hydrophilic environment in the interior of micelles in non-polar phase. Therefore, various interesting reaction systems can be constructed in these solutions different from aqueous micellar ones. It is known that the micellar size depends on the solubilized water content [4]. At the stoichiometric $\mathrm{H}_{2} \mathrm{O}$ concentrations below $0.37 \mathrm{M}$, all the water molecules are bound to the surfactant head group (bound water range). With increasing the stoichiometric $\mathrm{H}_{2} \mathrm{O}$ concentration above $0.37 \mathrm{M}$, the average aggregation number and the number of free water molecules entrapped in a reversed micelle increased rapidly (free water range) [4].

We found that $\mathrm{F}$ acted as considerably good photosensitizer for singlet oxygen production in DAP reversed micellar cyclohexanic solutions and the quantum yield for singlet oxygen production was highly enhanced by DAP reversed micelles depending on the solubilized water content.

In the present investigation, the DF photooxidation in DAP reversed micellar solutions containing $\mathrm{F}$ and $\mathrm{DF}$, and the optical properties

Abbreviations: F, fluorescein sodium; DF, 1,3-diphenylisobenzofuran; DAP, dodecylammonium propionate.

* Reprint requests to Prof. G. Tomita. 0340-5087/80/0600-0731/\$01.00/0 (absorption, fluorescence and phosphorescence) of $\mathrm{F}$ bound to DAP reversed micelles were dealt with changing the solubilized water content, and the information about the mechanism of the enhancement of the quantum yield for singlet oxygen production by DAP reversed micelles was sought for.

\section{Materials and Methods}

Cyclohexane, $\mathrm{KCr}\left(\mathrm{NH}_{3}\right)_{2}(\mathrm{NCS})_{4}$ (Raineck's salt), $\mathrm{DAP}$ and $\mathrm{F}$ purchased from Katayama Co. were guaranteed or extra pure reagents. DF obtained from Aldrich Chemical Co. was of special grade. Laboratory-distilled water was further distilled from alkaline $\mathrm{KMnO}_{4}$ solutions.

Reversed micellar solution was prepared by dissolving DAP in cyclohexanic solution containing DF at room temperature. The DAP cyclohexanic solution was stirred for ten minutes in the dark at $40^{\circ} \mathrm{C}$ after adding powdered $\mathrm{F}$ or aqueous $\mathrm{F}$ solutions at various water concentrations.

The concentration of $\mathrm{F}$ and $\mathrm{DF}$ in reversed micellar solutions were determined by absorbances at 500 and $415 \mathrm{~nm}$, respectively. The absorbances were measured with a Hitachi spectrophotometer type 356 . The reaction mixture in a quartz vessel $\left(1 \times 1 \times 4 \mathrm{~cm}^{3}\right)$ was irradiated with the yellow light isolated from a $150 \mathrm{~W}$ xenon lamp through a cut filter (colour glass filter, type V-Y 48, Toshiba Electric Co.) at $40{ }^{\circ} \mathrm{C}$.

The number of photons absorbed by $\mathrm{F}$ was determined by the chemical actinometry method (sensitive to $504 \mathrm{~nm}$ light) of Wegner and Adamson [5]. The actinometer cell containing a $5.0 \cdot 10^{-3} \mathrm{M}$ $\mathrm{KCr}\left(\mathrm{NH}_{3}\right)_{2}(\mathrm{NCS})_{4}$ aqueous solution at $\mathrm{pH} 5.3$ was placed just behined the target cell, and was illuminated for $20 \mathrm{~min}$ in the presence and absence of the target cell.

The fluorescence spectrum of $\mathrm{F}$ at room temperature was measured with a Hitachi type 203 spectrofluorimeter.

A glass tube with a diameter of $5 \mathrm{~mm}$ and a length of $20 \mathrm{~cm}$ was employed for the fluorescence 
and phosphorescence measurements at $77 \mathrm{~K}$. Anaerobic solutions were prepared by the freezepump-thaw cycles.

The phosphorescence spectrum and intensity of $F$ were measured by the phosphoroscope method. The excitation light was provided from a $150 \mathrm{~W}$ tungsten lamp through an interference filter (peak, $479 \mathrm{~nm}$; halfwidth, $16 \mathrm{~nm}$ ). The phosphoroscope (rotating cylinder type) was used for separating the phosphorescence from the fluorescence. A cylinder rotated at the constant rate of $3.6 \cdot 10^{3} \mathrm{rpm}$. The observation of the emission was delayed by $0.6 \mathrm{msec}$ after excitation. The durations of the observation and excitation were designed to be equally $2 \mathrm{msec}$ per one rotation of the cylinder. The phosphorescence intensity was detected with a photomultiplier (RCA 1C31034A) through a Nikon P-250 type monochromator, and its signal was fed to a homemade lock-in-amplifier. The phosphorescence decay was measured with a wave memory (NF model E-5001) and an oscilloscope (Hewlett Packard model $1725 \mathrm{~A}$ ).

\section{Results and Discussion}

When the DAP cyclohexanic solution (airbubbled) containing $\mathrm{F}$ and $\mathrm{DF}$ was irradiated with the yellow light ( $>480 \mathrm{~nm}$ ) absorbed by $\mathrm{F}$, the DF concentration exhibited an initial, linear decrease with the irradiation time followed by a saturation.

The decrease in DF concentration was caused by the oxidation of DF by singlet oxygen produced by the $\mathrm{F}$ photosensitization. DF is known to be highly reactive with singlet oxygen.

The initial rate $(\mathrm{R})$ of the $\mathrm{DF}$ oxidation increased linearly with increasing DF concentration in low $\mathrm{DF}$ concentration range as shown in Fig. 1. The initial slope in the curve of $\mathrm{R} v s \mathrm{DF}$ concentration

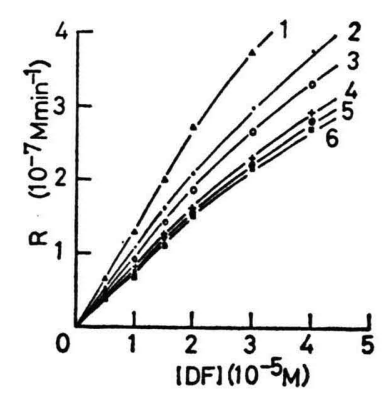

Fig. 1. The initial rate (R) of $D F$ oxidation as a function of DF concentration at various concentrations of solubilized water. $R$, initial rate; concentrations of $\mathrm{F}$ and DAP, $3.6 \cdot 10^{-6}$ and $8.0 \cdot 10^{-2} \mathrm{M}$, respectively; $\mathrm{H}_{2} \mathrm{O}$ concentrations for Curves $1,2,3,4,5$ and $6,0,0.2,0.3,0.4,0.5$ and $0.6 \mathrm{M}$, respectively; temperature, $40^{\circ} \mathrm{C}$.

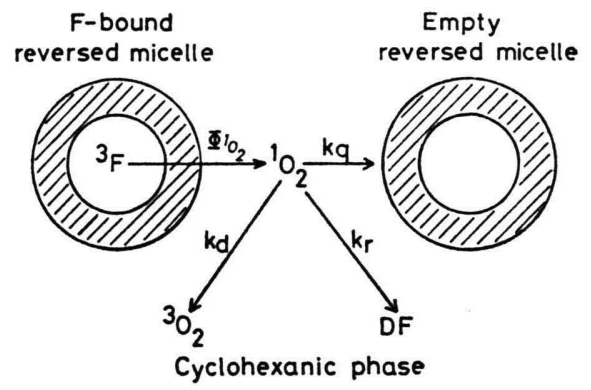

Fig. 2. Simplified diagram for the photochemical reaction in DAP reversed micellar solutions containing $F$ and DF. ${ }^{3} \mathrm{~F}$, triplet state of $\mathrm{F} ; \Phi^{1} \mathrm{O}_{2}$, quantum yield for singlet oxygen production in cyclohexanic phase; $k_{r}$, rate constant for DF oxidation by singlet oxygen; $\mathrm{k}_{\mathrm{d}}$, rate constant for physical decay of singlet oxygen in cyclohexane; $k_{q}$, rate constant for the quenching of singlet oxygen by empty DAP reversed micelles.

increased with decreasing the solubilized $\mathrm{H}_{2} \mathrm{O}$ content.

Simplified diagram for the photochemical reaction in DAP reversed micellar solutions containing $\mathrm{F}$ and DF is shown in Fig. 2, assuming that singlet oxygen is consumed by the DF oxidation, the quenching by empty micelles and the physical decay to triplet oxygen. $\mathrm{H}_{2} \mathrm{O}$ and $\mathrm{F}$ are bound to the interior of micelles ( $F$, hydrophylic), and DF may be dispersed in cyclohexanic phase (DF, hydrophobic). The quantum yield $\left(\Phi_{\mathrm{DF}}\right)$ for the $\mathrm{DF}$ oxidation is represented as follows.

$$
\Phi_{\mathrm{DF}}=\Phi^{1} \mathrm{O}_{2}\left(\frac{\mathrm{k}_{\mathrm{r}}[\mathrm{DF}]}{\mathrm{k}_{\mathrm{d}}+\mathrm{k}_{\mathrm{r}}[\mathrm{DF}]+\mathrm{k}_{\mathrm{q}}[\mathrm{M}]}\right),
$$

where $\Phi^{1} \mathrm{O}_{2}, \mathrm{k}_{\mathrm{r}}, \mathrm{k}_{\mathrm{d}}$ and $\mathrm{k}_{\mathrm{q}}$ are illustrated in the legend of Fig. 2, and [M] is the empty micellar concentration. The $k_{q}$ values were obtained by us at various $\mathrm{H}_{2} \mathrm{O}$ concentrations in the previous paper [3], and the $\mathrm{k}_{\mathrm{q}}[\mathrm{M}]$ value was estimated to be $3.0 \cdot 10^{4} \sim$ $5.1 \cdot 10^{4} \mathrm{sec}^{-1}$ for the $\mathrm{H}_{2} \mathrm{O}$ concentrations of $0 \sim 0.6 \mathrm{M}$. We assumed that one micelle bound one $\mathrm{F}$ molecule. The $\mathrm{F}$ concentration $\left(3.6 \cdot 10^{-6} \mathrm{M}\right)$ used was much less than that of reversed micelles (order of $10^{-3} \mathrm{M}$ ). The micellar concentration was determined using the aggregation number obtained by Correll et al. [4]. Since the $\mathrm{k}_{\mathrm{r}}$ and $\mathrm{k}_{\mathrm{d}}$ values were $5.3 \cdot 10^{8} \mathrm{M}^{-1} \cdot \mathrm{sec}^{-1}$ and $5.8 \cdot 10^{4} \mathrm{sec}^{-1}[3]$, respectively, $\mathrm{k}_{\mathrm{r}}[\mathrm{DF}]$ $\left(\leq 5.3 \cdot 10^{3} \mathrm{sec}^{-1}\right)$ could be neglected compared with $\mathrm{k}_{\mathrm{d}}+\mathrm{k}_{\mathrm{q}}[\mathrm{M}]$ in eq. (1) in the DF concentration range below $1.0 \cdot 10^{-5} \mathrm{M}$. Then, $\Phi_{\mathrm{DF}}$ is proportional to the $\mathrm{DF}$ concentration, and the slope is represented as follows. 


$$
\text { Slope }=\frac{\Phi^{1} \mathrm{O}_{2} \cdot \mathrm{k}_{\mathrm{r}}}{\mathrm{k}_{\mathrm{d}}+\mathrm{k}_{\mathbf{q}}[\mathrm{M}]} .
$$

The experimental values of $\Phi_{\mathrm{DF}}$ also exhibited a linear relation with the DF concentration below $1.0 \cdot 10^{-5} \mathrm{M}$. Accordingly, the quantum yield of singlet oxygen production $\left(\Phi^{1} \mathrm{O}_{2}\right)$ could be calculated at various $\mathrm{H}_{2} \mathrm{O}$ concentrations from eq. (2). The results obtained were shown in Fig. 3.

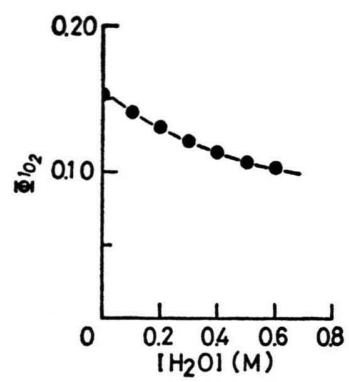

Fig. 3. Quantum yield $\left(\Phi^{1} \mathrm{O}_{2}\right)$ for singlet oxygen propuction as a function of $\mathrm{H}_{2} \mathrm{O}$ concentration. Concentrations of $\mathrm{F}$ and DAP, $3.6 \cdot 10^{-6}$ and $8.0 \cdot 10^{-2} \mathrm{M}$, respectively; temperature, $40^{\circ} \mathrm{C}$.

The quantum yield $\left(\Phi^{1} \mathrm{O}_{2}\right)$ decreased rapidly with increasing the $\mathrm{H}_{2} \mathrm{O}$ concentration below about $0.4 \mathrm{M}$ $\mathrm{H}_{2} \mathrm{O}$ (bound water range) and showed a gradual decrease above this $\mathrm{H}_{2} \mathrm{O}$ concentration (free water range). The $\Phi^{1} \mathrm{O}_{2}$ value at $0 \mathrm{M} \mathrm{H}_{2} \mathrm{O}$ was about 0.15 . This value was 1.5 times higher than that at $0.6 \mathrm{M}$ $\mathrm{H}_{2} \mathrm{O}$.

Usui [6] described that the quantum yield of singlet oxygen production by $\mathrm{F}$ photosensitization was 0.06 in aqueous solutions. The value obtained by Gollnick and Schenck [7] was 0.03 in water. It is notable that $\Phi^{1} \mathrm{O}_{2}$ was highly enhanced compared with that in water phase and strongly dependent on the solubilized $\mathrm{H}_{2} \mathrm{O}$ content, when $\mathrm{F}$ was introduced into DAP reversed micelles.

To seek for the information about the effects of DAP micelles and solubilized $\mathrm{H}_{2} \mathrm{O}$ on $\Phi^{1} \mathrm{O}_{2}$, the following experiments were carried out. The absorption and fluorescence spectra of $\mathrm{F}$ were measured in DAP reversed micellar solutions (Fig. 4). At room temperature, the absorption band at $490 \mathrm{~nm}$ in bulk aqueous $\mathrm{F}$ solutions red-shifted in DAP reversed micellar solutions. The band positions at 0 (Curve a) and $0.6 \mathrm{M} \mathrm{H}_{2} \mathrm{O}$ appeared at $500 \mathrm{~nm}$ and $499 \mathrm{~nm}$, respectively. The red-shift of the absorption band in DAP micellar solutions may be caused by the binding interaction between $\mathrm{F}$ and DAP micelle.

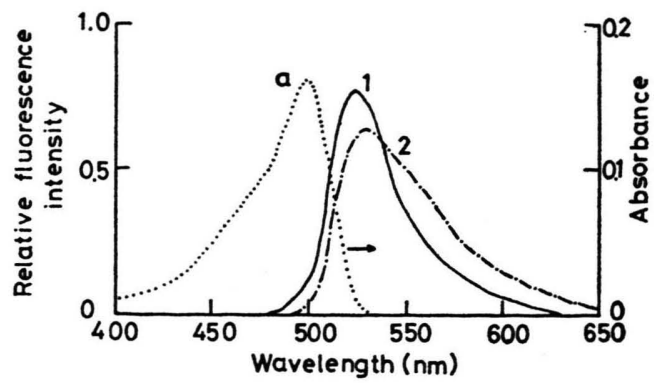

Fig. 4. Absorption and fluorescence spectra of F. Concentrations of $\mathrm{F}$ at room temperature and $77 \mathrm{~K}$, $3.6 \cdot 10^{-6}$ and $1.0 \cdot 10^{-5} \mathrm{M}$, respectively ; concentration of DAP, 8.0 $10^{-2} \mathrm{M}$; Curve 1, fluorescence spectrum of $\mathrm{F}$ solubilized in DAP micellar solutions containing $0 \mathrm{M} \mathrm{H}_{2} \mathrm{O}$ at room temperature; Curve 2, fluorescence spectrum of $\mathrm{F}$ solubilized in DAP micellar solutions containing $0 \mathrm{M} \mathrm{H}_{2} \mathrm{O}$ at $77 \mathrm{~K}$; Curve a, absorption spectrum of $\mathrm{F}$ solubilized in DAP micellar solutions containing $0 \mathrm{M} \mathrm{H}_{2} \mathrm{O}$ at room temperature.

The fluorescence band appeared at 526 and $525 \mathrm{~nm}$ in DAP reversed micellar solutions containing 0 (Curve 1) and $0.6 \mathrm{M} \mathrm{H}_{2} \mathrm{O}$, respectively, at room temperature. The band position in aqueous $\mathrm{F}$ solution was $498 \mathrm{~nm}$ at room temperature. The fluorescence band red-shifted largely at $77 \mathrm{~K}$ and appeared at 530 and $525 \mathrm{~nm}$ for the $\mathrm{H}_{2} \mathrm{O}$ contents of 0 (Curve 2) and $0.6 \mathrm{M}$, respectively.

Next, the fluorescence intensity at room temperature are plotted against the $\mathrm{H}_{2} \mathrm{O}$ content in Fig. 5. The fluorescence intensity decreased slightly with increasing the $\mathrm{H}_{2} \mathrm{O}$ content, but it was highly quenched compared with that in bulk aqueous solutions. The phosphorescence could not be measured at room temperature.

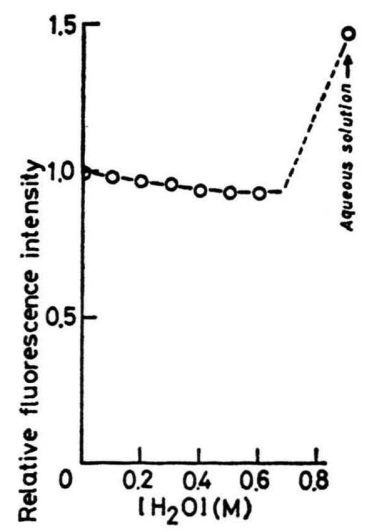

Fig. 5. Fluorescence intensity as a function of $\mathrm{H}_{2} \mathrm{O}$ concentration at room temperature. Concentrations of $\mathrm{F}$ and DAP, 3.6 $10^{-6}$ and $8.0 \cdot 10^{-2} \mathrm{M}$, respectively. 


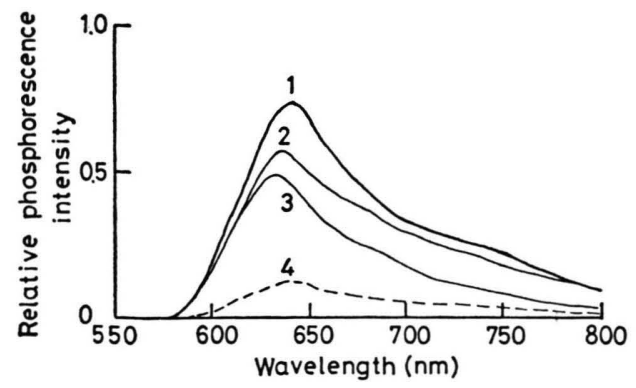

Fig. 6. Phosphorescence spectra of $\mathrm{F}$ at $77 \mathrm{~K}$. Concentrations of $\mathrm{F}$ and DAP, $1.0 \cdot 10^{-5}$ and $8.0 \cdot 10^{-2} \mathrm{M}$, respectively; $\mathrm{H}_{2} \mathrm{O}$ concentrations for Curves 1, 2, 3 and $4,0,0.2,0.6 \mathrm{M}$ in anaerobic samples and $0 \mathrm{M}$ in $\mathrm{O}_{2}$-bubbled sample, respectively.

Fig. 6 shows the phosphorescence spectra of $\mathrm{F}$ at various $\mathrm{H}_{2} \mathrm{O}$ concentrations at $77 \mathrm{~K}$. The phosphorescence band blue-shifted from 640 to $630 \mathrm{~nm}$ with the increase of the $\mathrm{H}_{2} \mathrm{O}$ content from 0 to $0.6 \mathrm{M}$. The phosphorescence intensity depended on the $\mathrm{H}_{2} \mathrm{O}$ content, and it decreased with increasing the $\mathrm{H}_{2} \mathrm{O}$ content. Furthermore, the phosphorescence intensity was highly quenched by $\mathrm{O}_{2}$. The fluorescence and phosphorescence intensities are shown in

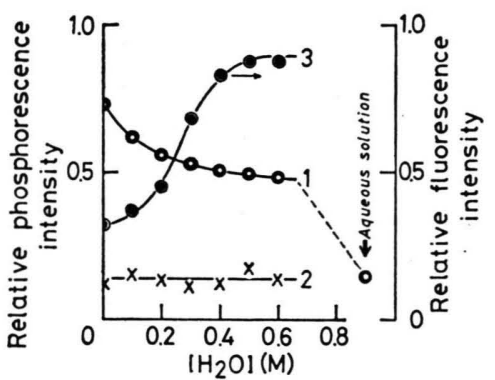

Fig. 7. Fluorescence and phosphorescence intensities as a function of $\mathrm{H}_{2} \mathrm{O}$ concentration at $77 \mathrm{~K}$. Concentrations of $\mathrm{F}$ and DAP, $1.0 \cdot 10^{-5}$ and $8.0 \cdot 10^{-2} \mathrm{M}$, respectively; Curves 1,2 and 3 , phosphorescence intensities of anaerobic samples and $\mathrm{O}_{2}$-bubbled samples, and fluorescence intensity of anaerobic (or $\mathrm{O}_{2}$-bubbled) sample, respectively.

Fig. 7 as a function of the $\mathrm{H}_{2} \mathrm{O}$ concentration at $77 \mathrm{~K}$.

The phosphorescence intensity of anaerobic samples increased rapidly in the bound water range $\left(<0.4 \mathrm{M} \mathrm{H}_{2} \mathrm{O}\right)$ with decreasing the water content (Curve 1), but $\mathrm{O}_{2}$-bubbled samples had low phosphorescence intensities (strong quenching by $\mathrm{O}_{2}$ ) nearly independent of the $\mathrm{H}_{2} \mathrm{O}$ content (Curve 2).
Further, the phosphorescence was highly enhanced in anaerobic micellar solutions compared with that in anaerobic water solutions as seen in Fig. 7. The fluorescence was not quenched by $\mathrm{O}_{2}$.

As seen in Fig. 4, F bound to the interior of DAP reversed micelle had the absorption and fluorescence bands at longer wavelengths than those of free $\mathrm{F}$. The fluorescence intensity was highly quenched by binding of $\mathrm{F}$ to micelle (Fig. 5). Moreover, the absorption and fluorescence band positions, and the fiuorescence intensity changed by the solubilized $\mathrm{H}_{2} \mathrm{O}$ content (Figs. 4 and 5). These indicate that the electronic state of $\mathrm{F}$ is highly affected by the adsorptive interaction between $\mathrm{F}$ and DAP micelle. Singlet oxygen is considered to be produced through the transfer of the triplet energy of $\mathrm{F}$ to oxygen. For this reason, the singlet oxygen formation depends strongly on the population of the triplet state of $\mathrm{F}$. At $77 \mathrm{~K}$, the increase in the phosphorescence intensity and the decrease in the fluorescence intensity with decreasing the solubilized water content, and the enhancement of the phosphorescence intensity by the binding of F to DAP micelle as shown in Fig. 7 suggest that the intersystem crossing from the excited singlet state of $\mathrm{F}$ to the triplet state was enhanced by the binding interaction between $\mathrm{F}$ and DAP micelle. This interaction may be weakened with increasing the solubilized water content. These may cause high values of $\Phi^{1} \mathrm{O}_{2}$ in DAP micellar solutions and the dependence of $\Phi^{1} \mathrm{O}_{2}$ on the solubilized $\mathrm{H}_{2} \mathrm{O}$ content as seen in Fig. 3.

The lifetime of the triplet state of $\mathrm{F}$ has been obtained as $20 \mathrm{msec}$ by Lidqvist using the T-T absorption method [8] in bulk aqueous solutions at room temperature. The lifetime of the phosphorescent state obtained by us in DAP micellar solutions at $77 \mathrm{~K}$ was about $450 \mathrm{msec}$ at the $\mathrm{H}_{2} \mathrm{O}$ content of $0 \sim 0.6 \mathrm{M}$. We could not determine the lifetime of the $\mathrm{F}$ triplet state at room temperature owing to extreme weakness of the phosphorescence, but the lifetime of the $\mathrm{F}$ triplet state might be highly lengthened inside DAP micelle compared with that of free F. This is also another important factor responsible for the high value of $\Phi^{1} \mathrm{O}_{2}$ in DAP micellar solutions.

At present, we can not go into further mechanism for the effects of DAP micelle and solubilized water on $\Phi^{1} \mathrm{O}_{2}$. We must make clear up the structure of 
DAP micelle depending on the solubilized water, micelle, and the polarity and viscosity inside DAP the binding site and electronic state of $\mathrm{F}$ in DAP micelle in future.

[1] N. Miyoshi and G. Tomita, Z. Naturforsch. 33b, 622 (1978).

[2] N. Miyoshi and G. Tomita, Photochem. Photobiol. 29, 527 (1979).

[3] N. Miyoshi and G. Tomita, Z. Naturforsch. 34b, 339 (1979).

[4] G. Correll, R. N. Chesser, III, F. Nome, and J. H. Fendler, J. Am. Chem. Soc. 100, 1254 (1978).
[5] E. E. Wegner and A. W. Adamson, J. Am. Chem. Soc. 88, 394 (1966).

[6] Y. Usui, Chemistry Letters (Japan) 1973, 743.

[7] K. Gollnick and G. O. Schenck, Pure Appl. Chem. 9, 507 (1964).

[8] L. Lindqvist, J. Phys. Chem. 67, 1701 (1963). 